\title{
Entendendo a solidão do idoso
}

\author{
Renata Francioni Lopes*, Maria Teresinha Francioni Lopes", Vilma Duarte Camara***
}

\section{Resumo}

A solidão afeta as atividades de vida diária e a qualidade de vida do idoso. É pouco investigada e reconhecida pelos profissionais de geriatria e gerontologia. $\mathrm{O}$ objetivo deste trabalho foi estudar a solidão no idoso, analisando sua relação com o isolamento social, a depressão, o luto e o abandono. Estudamos 132 pacientes, 96 mulheres e 36 homens, com sessenta anos ou mais, do Centro de Referência de Geriatria e Gerontologia da Universidade Federal Fluminense. Eles responderam a um questionário sobre seus sentimentos de solidão. Dos entrevistados $83,3 \%$ concordaram que viver sozinho pode diminuir a qualidade de vida; 55,0\% apontaram a aposentadoria como fator para o isolamento social e $80,3 \%$ disseram que sintomas depressivos levam ao isolamento social. A maioria dos entrevistados não morava sozinho $(85,6 \%)$, embora $35,4 \%$ das mulheres $(n=34)$ e $22,2 \%$ dos homens $(n=8)$ se sentissem solitários. Somente $16,7 \%$ concordaram que hoje os filhos cuidam dos pais. Depressão, luto, isolamento social e abandono foram analisados nos indivíduos ditos solitários. Nos solitários 40,4\% são, provavelmente, deprimidos e desamparados; $88,09 \%$ não vão a um clube nem fazem qualquer atividade em grupo. O luto foi relacionado ao sentimento de solidão mais em mulheres (18/34) que em homens (1/8). A manutenção do convívio familiar e do trabalho parece evitar o sentimento de solidão. A construção de programas interdisciplinares de promoção de saúde, que incluam educação em família e inclusão social, constitui a principal meta para prevenir ou reduzir o sentimento de solidão dos idosos.

Palavras-chave: Idoso. Solidão.

\section{Introdução}

A solidão é o estado de quem se sente só, traduz isolamento. (FERNANDES; LUFT; GUIMARÃES, 2000). A solidão provoca um sentimento de vazio interior, que pode estar presente no ser humano nas diferentes fases da vida, e tende a ser mais frequente com o envelhecimento. Fatores psicológicos e sociais parecem estar relacionados com o seu surgimento,

* Doutora em Medicina pela Universidade Federal do Rio de Janeiro. Geriatra do Hospital Universitário Antônio Pedro - Campus Mequinho - da Universidade Federal Fluminense.

** Psicóloga clínica. Especialista em Gerontologia e Geriatria Interdisciplinar pela Universidade Federal Fluminense.

**** Doutora em Medicina pela Universidade Federal do Rio de Janeiro. Professora Associada II de Neurologia e Coordenadora do Programa de Geriatria e Gerontologia Interdisciplinar do Hospital Universitário Antônio Pedro - Campus Mequinho - da Universidade Federal Fluminense. Endereço para correspondência: Rua Passos da Pátria, 105/101, Bairro São Domingos, Niterói - RJ. CEP 24210-240. E-mail: vdcamara@globo. com

$\hookrightarrow$ Recebido em março de 2009 - Avaliado em junho de 2009.

$\rightarrow$ doi:10.5335/rbceh.2009.036 
como a depressão, o luto, o isolamento social e o abandono. (GOLDFARB, 1998; GUIDETTI; PEREIRA, 2008; PEDROZO; PORTELLA, 2003; PORTO; KOLLER, 2006; WORDEN, 1998).

A população mundial de idosos está crescendo continuamente e a solidão interfere na qualidade de vida da pessoa, que se priva do convívio, empobrecendo o conhecimento adquirido no contato social e afetando as atividades de vida diária. (LITVOC; BRITO, 2004; PAPALÉO NETTO, 2002).

A incapacidade física e outras comorbidades, como as demências, podem contribuir para o isolamento social e a depressão, especialmente nos idosos. Embora relacionada com as condições descritas, a solidão é uma condição pouco investigada e reconhecida pelos profissionais de geriatria e gerontologia.

O objetivo deste estudo foi definir a solidão no idoso, na ótica do próprio idoso, analisando sua relação com o isolamento social, a depressão, o luto e o abandono.

\section{Materiais e métodos}

Foram pesquisados 132 pacientes, homens e mulheres maiores de sessenta anos, que frequentam o Centro de Geriatria e Gerontologia da Universidade Federal Fluminense- Campus Mequinho e o Setor Ambulatorial Geriátrico do Hospital Universitário Antonio Pedro. Antes foram excluídos aqueles que não conseguiam se expressar por meio da fala.

O trabalho foi embasado em levantamento bibliográfico dos últimos dez anos das fontes de indexação e repositório de artigos Medline, Lilacs, Pubmed, utili- zando as palavras-chaves: solidão, luto, isolamento social, abandono e depressão.

Foi aplicado um questionário organizado em duas partes, sendo a primeira responsável pela caracterização dos idosos com as variáveis sociodemográficas (idade, sexo, estado civil, escolaridade) e a segunda com questões exploratórias para apontar o número de casos de solidão, os possíveis fatores relacionados (depressão, luto, isolamento social e abandono) e, também, mostrar a visão do idoso sobre solidão e os reflexos no cotidiano, com o depoimento livre dos voluntários.

Os homens e mulheres entrevistados foram separados por faixa etária ( 60 a 69 anos, 70 a 79 anos e 80 anos ou mais) e se sentiam solidão ou não, para a seleção de um depoimento por grupo. A escolha do depoimento foi aleatória nos diferentes grupos: mulheres de 60 a 69 anos que sentiam solidão, mulheres de 60 a 69 anos que não sentiam solidão; homens de 60 a 69 anos que sentiam solidão, homens de 60 a 69 anos que não sentiam solidão. Da mesma forma se procedeu em relação aos demais grupos de homens e mulheres de 70 a 79 anos e, também, com os de 80 anos ou mais.

Foi utilizada para o cálculo a percentagem para a obtenção dos resultados das entrevistas do trabalho de campo. Também foi feita uma análise dos dados qualitativos coletados.

\section{Resultados}

Dos 132 entrevistados 96 eram mulheres e 36, homens. Caracterizando por faixa etária, a maioria era de mulheres de 60 a 69 anos $(n=58)$; o restante dos 
entrevistados eram de mulheres de 70 a79 anos $(\mathrm{n}=34)$, mulheres de 80 anos ou mais $(\mathrm{n}=4)$, homens de 60 a 69 anos $(\mathrm{n}=19)$, homens de 70 a79 anos $(\mathrm{n}=14)$ e homens de 80 ou mais $(n=3)$. A maioria tinha o primeiro grau completo.

$\mathrm{Na}$ abordagem do tema solidão, 42 entrevistados responderam sim para questão “O $\operatorname{Sr}(a)$ sente solidão?", correspondendo a $35,4 \%$ do total das mulheres $(60$ a 69 anos $\mathrm{n}=19 ; 70$ a 79 anos $\mathrm{n}=12$ e 80 ou mais anos com solidão $\mathrm{n}=3$ ) e a $22,2 \%$ dos homens ( 60 a 69 anos que sentem solidão $\mathrm{n}=5$; 70 a 79 anos $\mathrm{n}=2,80$ ou mais $\operatorname{anos} \mathrm{n}=1$ ).

Analisando os grupos de casados, de 33 mulheres casadas de 60 a 69 anos, dez sentem solidão; de 18 homens casados de 60 a 69 anos, quatro sentem solidão; de 11 mulheres de 70 a 79 anos, casadas, dois sentem solidão; de 11 homens de 70 a 79 anos, casados, um sente solidão; de duas mulheres casadas de 80 anos ou mais, ambas sentem solidão; de dois homens casados de oitenta anos ou mais, nenhum sente solidão. Além disso, buscou-se, indiretamente, detectar um possível quadro depressivo. Dos solitários, 40,5\% afirmaram não estarem alegres na maior parte do tempo, entretanto apenas um respondeu que não vale a pena viver como está vivendo.

Considerando convívio versus isolamento social nos solitários, $21,4 \%$ não visitam amigos; $50 \%$ não participam de projetos de terceira idade; $88,1 \%$ não frequentam clube ou outra atividade em grupo; $33,3 \%$ preferem ficar em casa em vez de sair e passear. A maioria dos entrevistados não mora sozinho $(85,6 \%)$. Dos solitários 40,5\% se sentem abando- nados, e apenas $26,2 \%$ recebem visitas em casa sempre.

A maioria das mulheres era constituída de viúvas e a dos homens, de casados. O sentimento de luto com perda de pessoa querida recente foi mais frequente nas mulheres que nos homens que sentem solidão (18 das 34 mulheres solitárias e um dos oito homens solitários). Sobre o tema "relação entre pais e filhos", 16,7\% acham que atualmente os filhos cuidam dos pais idosos e $99,2 \%$, que os filhos devem cuidar dos pais.

Verificou-se que nenhum homem gosta de morar sozinho e que $83,3 \%$ dos entrevistados concordam que morar sozinho pode contribuir de forma negativa para a saúde, influenciando na qualidade de vida. Entre os entrevistados, $45,5 \%$ acreditam que a velhice contribui para a solidão e $56,1 \%$, que a aposentadoria favorece a solidão. Em relação à tristeza, $80,3 \%$ dos pesquisados afirmaram que a tristeza produz a solidão

\section{Depoimentos}

Dos sujeitos entre 60 a 69 anos:

Pago água, luz, não dá para lazer. O que sinto é ingratidão. Solidão é num domingo sua comidinha gostosa não descer. A casa vazia! Casou o primeiro filho, o segundo... As pessoas lutam pela sobrevivência. As pessoas querem status, não convivem. É difícil! Muito triste! (Mulher de 66 anos, separada, com primeiro grau completo, que sente solidão)

Para mim não existe solidão. Estou sempre feliz, trabalhando, cuidando do meu cachorro negão, que me beija e abraça; cuido também do galo e das galinhas. Dou sempre graças a Jesus e assim vou vivendo. (Mulher 67 anos, solteira, analfabeta, que não sente solidão) 
A pessoa se aposenta e deve procurar o que fazer com quem conviver; nunca ficar só. Tenho que me acostumar com a velhice e as perdas porque não somos eternos. (Homem de 62 anos, casado, com segundo grau completo, que sente solidão)

Solidão na velhice é terrível, ninguém vive sem família. Quando não tenho o que fazer cavo a rua, planto, trabaIho. É coisa abençoada trabalhar. (Homem de 68 anos, jardineiro, casado, que não estudou e que não sente solidão)

Dos sujeitos entre 70 a 79 anos:

Solidão é ruim! (Mulher de 73 anos, casada, com primeiro grau completo, que sente solidão)

Procurar ler para se informar e conversar muito, estratégias para vencer a solidão. Carinho é importante em qualquer idade. O convívio é imprescindível. (Mulher de 75 anos, viúva, com primeiro grau completo, que não sente solidão)

A solidão na velhice existe. Nunca fique só procure alguém, passe algumas horas com alguém. Tenho mulher e filhas e às vezes me sinto só. Muitos ficam sozinhos. A mulher tem mais condições de ficar sozinha. O homem não tem condições, é triste a solidão. O homem só, se revolta, se desespera. (Homem de 70 anos, casado, com segundo grau completo, que sente solidão)

Não gosto de solidão não, fujo dela. (Homem de 76 anos, casado, com primeiro grau completo, que não sente solidão)

Dos sujeitos entre oitenta anos ou mais:

Existe solidão pra alguns abandonados, alguns não conversam com os outros têm orgulho, não trocam opinião aí sofrem. (MuIher de 80 anos, casada, com primeiro grau incompleto, que sente solidão)
Não sei o que é solidão; canto muito. É muito, muito importante encontrar as pessoas! (Mulher de 85 anos, viúva, com primeiro grau incompleto que não sente solidão, mora com três netos)

Solidão, sinônimo de tristeza! A solidão produz a tristeza. (Homem de 84 anos, viúvo, com primeiro grau completo, que sente solidão, mora com o filho)

Ainda trabalho; acho a solidão muito triste, embora ache quem gosta dela. (Homem 84 anos, casado, com superior completo, que não sente solidão)

\section{Discussão}

Observou-se nesta pesquisa que as mulheres se sentem mais solitárias que os homens. Em parte, isso pode ser justificado pelo estado civil, visto que a maioria das mulheres entrevistadas era constituída de viúvas e a dos homens, de casados. Porém, as mesmo analisando os casados, as mulheres tendem a sentir mais solidão que os homens. Mesmo com o envelhecimento, o sentimento de solidão continua se diferenciando por gênero. Em virtude de um maior período de vida da mulher e da consequente feminização da velhice, o número de viúvas é maior do que o de viúvos. Além de a mulher ter uma vida mais longa, normalmente, por fatores culturais, em todo o mundo, ela se casa mais jovem do que o homem. O resultado da conjunção desses dois fatores é um período mais extenso de solidão das mulheres viúvas (ou separadas) em relação aos homens. (VERAS, 1988).

Ilustrou-se bem neste estudo, apesar de pequeno número de pacientes muito 
idosos, que mulheres de oitenta anos ou mais se sentem mais solitárias que homens de oitenta anos ou mais. Parece que o sentimento de solidão é sentido mais em mulheres do que em homens pela forma de construção e expressão do afeto diferente entre os sexos. Entretanto, isso não minimiza a importância da investigação desse sentimento em homens e mulheres, visto que os problemas de saúde nos idosos, causados por patologias múltiplas, são agravados pela solidão. (GRIFFITHS et al., 1987). A "solidão que dói" descrita em homens solteiros, divorciados e viúvos foi associada a maior suscetibilidade a doenças como hipertensão, problemas cardíacos, câncer na garganta e pneumonia. (WAITE; GALLAGHER, 2001).

O sentimento de tristeza é o que mais contribui para solidão, segundo os idosos pesquisados. Essa tristeza pode estar relacionada ao sentimento de luto (principalmente em mulheres), ser sintoma de um quadro depressivo, estar relacionada a uma debilidade física ou a um problema social. (PEDROZO; PORTELLA, 2003; PORTO; KOLLER, 2006; WORDEN, 1998; GRIFFITHS et al., 1987).

O luto pode ser compreendido como um processo normal e penoso, necessário para superação da perda. Esse processo é considerado como uma reação natural ao rompimento de um vínculo, que produz uma dor pela morte de alguém. Essa dor precisa ser elaborada, pelo organismo a fim de ser superada. É durante o esforço do idoso para elaboração da perda que ele pode se distanciar total ou parcialmente do que ocorre ao seu redor, o que em alguns casos pode facilitar, e em outros, obstaculizar o enfrentamento da situação. (WORDEN, 1998).

Uma proporção significativa de idosos apresenta depressão, um problema de saúde que causa impacto na morbidade, mortalidade e qualidade de vida. (WAGENAAR et al., 2002; SHARP; LIPSKY, 2002; ALEXOPOULOS et al., 2002).

A prevalência da depressão em 173 pacientes acima de 65 anos foi de $16 \%$ num Centro de Saúde na Espanha. O sexo feminino ( $p<0,0001)$, idade maior ou igual a $75 \operatorname{anos}(\mathrm{p}=0,040)$ e isolamento social $(p<0,0001)$ foram variáveis fortemente associadas com depressão. (GARCIA SERRANO; TOBIAS FERRER, 2001).

$\mathrm{O}$ idoso frequentemente apresenta como sinal de depressão a desmotivação. (THOMAS et al., 1999). A motivação é ameaçada por consequência de dependência física que altera a sua autoestima; a dificuldade de se adaptar às novas situações pode gerar um isolamento social e, aumentando a desmotivação precipitar um quadro depressivo. (THOMAS et al., 1999). Uma vida ativa baseada no entretenimento e na comunicação pode evitar no idoso a depressão, o aparecimento de doenças físicas e mentais, a carência afetiva e emocional. (GUIDETTI; PEREIRA, 2008).

Sintomas depressivos e demência são os distúrbios psiquiátricos mais frequentes na velhice. Doenças somáticas, isolamento social e diminuição da capacidade funcional interferem nas atividades da vida diária e na participação social, sendo fatores de risco relevantes para o surgimento dos quadros depressivos. 
(GUTZMAN, 2000; CORREAA, 1996). Entretanto, neste estudo não foram aplicadas as escalas de mini-exame do estado mental, de depressão geriátrica, as de atividades de vida diária ou as de atividades instrumentais de vida diária. Assim, não pudemos caracterizar os deprimidos ou portadores de outras doenças crônicas ou incapacitantes.

Embora não se possa com esta pesquisa afirmar que a solidão é sintoma ou causa de depressão, pudemos suspeitar uma associação. Dos solitários, pouco menos da metade afirmou não estar alegre a maior parte do tempo e apenas um afirmou que não vale a pena viver como está vivendo agora. Como as perguntas relacionadas a um possível quadro depressivo eram muito diretas, há a possibilidade de a resposta do idoso não ter coincidido com o seu real sentimento.

$\mathrm{Na}$ psicologia social, isolamento significa a privação de contatos sociais, a tendência a evitar contatos sociais. Em psicanálise, o isolamento constitui um processo semelhante, em seus efeitos, à repressão, mas distingue-se desta pelo fato de o impulso ou desejo subjacente ser conscientemente reconhecido, embora a sua relação com o comportamento real não o seja. $\mathrm{O}$ isolamento é sintoma comum na neurose obsessivo-compulsiva, mas é raro encontrar essa tendência nas pessoas normais. (FREUD, 1999).

Todo ser humano - infante, jovem ou idoso - para um bem-estar biopsicossocial necessita conviver com outras pessoas. A prática de atividades em grupo traz mudanças positivas na comunicação dos idosos. Nesse sentido, as relações sociais entre mais velhos estimulam a mente e o pensamento, tendo múltiplos efeitos benéficos sobre a saúde e bem-estar, contribuindo para a melhoria da qualidade de vida. (GUIDETTI; PEREIRA, 2008).

Como a desmotivação pode precipitar a depressão e o isolamento social pode ser consequência da desmotivação, a análise do convívio versus isolamento social auxilia no diagnóstico dos solitários com potencial para depressão ou agravamento de um quadro depressivo já instalado. O idoso privado de convívio sofre; deixando de exercer atividades antes vivenciadas com prazer, torna-se triste e limitado. Com esses questionamentos Participa de projeto para terceira idade? Visita amigos? Frequenta clube? Prefere ficar em casa ou sair para passear? - é possível traçar um plano terapêutico com metas a serem alcançadas, com o objetivo de estimular o convívio social.

Metade dos solitários não participa de projeto para terceira idade; a maioria não frequenta clube ou qualquer outra atividade em grupo; um terço dos solitários prefere ficar em casa em vez de sair e passear; surpreendentemente, quase $80 \%$ dizem ter o hábito de visitar amigos apesar de apenas $26,2 \%$ deles receberem visitas em casa. A questão é: Visitam muito e recebem poucas visitas? Ou tentam mascarar a realidade de isolamento social?

Sentir solidão não é sinônimo de abandono para cerca de $60 \%$ dos solitários. Os entrevistados, em sua maioria, não moram sozinhos, geralmente moram com o cônjuge ou filhos. A solidão é um sentimento de vazio interior proveniente da falta de interação, de diálogo e de convívio, que pode ocorrer nos casos de 
ninho vazio. (PEDROZO; PORTELLA, 2003). Praticamente todos dizem que os filhos devem cuidar dos pais, entretanto uma parcela mínima diz que atualmente os filhos cuidam dos pais idosos.

O mercado de trabalho competitivo, a sobrevivência, a falta de informação sobre educação e respeito ao idoso entre pais e filhos parecem justificar, em parte, o modelo familiar de hoje. Mesmo com a estrutura familiar "adoecida", o idoso, em geral, não prefere morar só. A família é o núcleo por excelência no qual os idosos buscam apoio para sua vivência afetiva. $\mathrm{O}$ carinho e o respeito da família contribuem decisivamente para um final de vida feliz. (PORTO; KOLLER, 2006). Mais de $80 \%$ dos entrevistados concordam que morar sozinho pode contribuir de forma negativa para a saúde, influenciando na qualidade de vida. Felizmente, os idosos não veem a velhice contribuindo para a solidão em quase $55 \%$ dos casos. Esses idosos aprenderam a superar suas limitações físicas, quer participando de projetos de terceira idade, quer continuando a trabalhar, cuidando de netos, viajando, ou criando outras estratégias para a continuidade da vida com melhor qualidade. Com base nos depoimentos apresentados, demonstrou-se como o convívio e a família auxiliam o idoso a se relacionar com os outros e se sentir parte inserida da coletividade, ainda como ser social.

Como já é esperado, a aposentadoria favorece a solidão, gerando um sentimento de vazio nos idosos. (PEDROZO; PORTELLA, 2003). A importância e a exaltação máximas conferidas ao trabalho na sociedade contemporânea concedem ao papel de trabalhador lugar de destaque entre os papéis sociais representativos do eu. Os programas de readequação social pré-aposentadoria parecem minimizar os sentimentos de inferioridade, rejeição, medo, abandono, que podem favorecer o sentimento de solidão. Ressignifica-se o conceito de trabalho, que constitui a identidade de trabalhador, de acordo com os limites sociais impostos: trata-se de ser ativo em contraposição ao não ativo. Nessa perspectiva, são buscadas atividades remuneradas ou não, preferentemente no espaço público, como forma de garantir reconhecimento social. É o que oportuniza a experiência de se sentir vivo, já que sua ausência é associada a morte, a exclusão e a segregação numa sociedade pautada pelo valor produtivo. (CARLOS et al., 1999).

$\mathrm{Na}$ análise dos depoimentos dos idosos também se observou a importância da manutenção do trabalho, mesmo que não remunerado, até idades mais avançadas, como mecanismo de satisfação pessoal. O bem-estar subjetivo proporcionado pelo trabalho parece "imunizar" o idoso contra o sentimento de solidão. $\mathrm{O}$ efeito do trabalhador sadio está presente entre idosos, manifestando-se principalmente pela maior autonomia e mobilidade física dos que trabalham. Idosos com boas condições de saúde, com autonomia física e mental, mantêm boas perspectivas de vida e podem assumir papéis relevantes na sociedade. (GIATTI; BARRETO, 2003). 


\section{Conclusão}

A velhice não é sinônimo de solidão. Depressão, luto, isolamento social e abandono podem estar relacionados à solidão. Segundo os idosos, a tristeza é o que mais leva ao sentimento de solidão. A manutenção do trabalho e dos vínculos familiares, pela análise do discurso desses idosos, parece evitá-la. Compreendendo a solidão na ótica do idoso, a estratégia primordial para erradicá-la ou minimizá-la é promover ações geriátricas e gerontológicas que garantam a qualidade de vida dos idosos nos âmbitos biológico, psicológico e social.

Deve-se pensar em programas préaposentadoria, em campanhas de educação no lar e escolar de respeito ao idoso, com o intuito de preservar "o ser social da pessoa idosa" no mundo atual.

\section{Understanding the solitude in the elderly}

\section{Abstract}

Solitude affects daily activities and quality life of elderly people. It is less investigated and recognized by geriatrics and gerontology professionals. The objective of this article was study the solitude in the elderly analysing the relation with social isolation, depression, mourning and helplessness. We studied 132 patients, 96 women and 36 men, with sixty years or more, of The Geriatric and Gerontological Center of Universidade Federal Fluminense. They answered one questionary about their feelings of solitude. Of them, $83,3 \%$ agreed that live alone may decrease quality life; $55,1 \%$ associated that retirement contribute to social isolation and $80,3 \%$ said that depressive symptoms leads to social isolation. The majority of the interviewers didn't live alone $(85,6 \%)$, although we detected $35,4 \%$ of women $(n=34)$ and $22,2 \%$ of men $(n=8)$ felling solitaires. Only $16,7 \%$ agreed that nowadays the sons care of their parents. Depression, mourning, social isolation and helplessness were analyzed in solitary persons. In solitaires $40,5 \%$ were probably depressive and abandoned; $88,09 \%$ didn't go to a club or make any group activity. Sadness after relative's death was related to solitude greater in women (18/34) than in men (1/8). A family and work connection seems to prevent solitude. The principal goal to prevent or reduce loneliness in elderly is interdisciplinary healthy promotion programs that include family education and social inclusion.

Key words: Elderly. Loneliness.

\section{Referências}

ALEXOPOULOS, G. S. et al. Comorbidity of late life depression: an opportunity for research on mechanisms and treatment. Biol. Psychiatry, v. 52, n. 6, p. 543-558, 2002.

CARLOS, S. A. et al. Identidade, aposentadoria e terceira idade. Estudos Interdisciplares em Envelhecimento, Porto Alegre, v. 1, n. 1, p. 77-89, 1999.

CORRÊA, A. C. O. Envelhecimento, depressão e doença de Alzheimer. Belo Horizonte: Health, 1996.

FERNANDES, F.; LUFT, C. P.; GUIMARÃES, F. M. Dicionário Brasileiro Globo. 53. ed. São Paulo: Globo, 2000.

FREUD, S. Neurose, psicose e velhice. In: MESSY, J. A pessoa idosa não existe: uma abordagem psicanalítica da velhice. São Paulo: Aleph, 1999. p. 11-13.

GARCIA SERRANO, M. J.; TOBIAS FERRER, J. Prevalence of depression in patients over 65 years of age. Profile of the elderly at risk. Rev. Aten. Primaria, v. 27, s. n., p. 484-488, 2001. 
GIATTI, L.; BARRETO S. M. Saúde, trabalho e envelhecimento no Brasil. Cadernos de Saúde Pública, São Paulo, v. 19, n. 3, p. 759-771, 2003.

GOLDFARB, L. C. Corpo, tempo e envelhecimento. São Paulo: Casa do Psicólogo, 1998.

GRIFFITHS, R. A. et al. Depression dementia and disability in the elderly. British Journal of Psychiatry, v. 150, s. n., p. 482493, 1987.

GUIDETTI, A. A.; PEREIRA, A. S. A importância da comunicação na socialização dos idosos. Revista de Educação, São Paulo, n. XI, n. 11, p. 119-136, 2008.

GUTZMAN, H. Diagnosis and therapy of depression in advanced age. Therapeutische Umschau. Revue Therapeutique, v. 57, n. 2, p. 95-99, 2000.

LITVOC, J.; BRITO, F. C. Envelhecimento: prevenção e promoção da saúde. São Paulo: Atheneu, 2004.

PAPALÉO NETTO, M. Gerontologia: a velhice e o envelhecimento em visão globalizada. São Paulo: Atheneu, 2002.

PEDROZO, S. K.; PORTELLA, M. R. Solidão na velhice: Algumas reflexões a partir da compreensão de um grupo de idosos. Boletim da Saúde, Porto Alegre, v. 17, n. 2, p. 171-183, 2003.

PORTO, I.; KOLLER, S. H. Violência na família contra pessoas idosas. Interações, São Paulo, v. XII, n. 22, p. 105-142, 2006.

SHARP, L. K.; LIPSKY, M. S. Screening for depression across the lifespan: a review of measures for use in primary care settings. Am. Fam. Physician., v. 66, n. 6, p. 1001-1008, 2002.

THOMAS, P. J. et al. More tolerance in management of unmotivated elderly family members. Praxis, v. 88, n. 6, p. 223-232, 1999.

VERAS, R. P. Considerações acerca de um jovem país que envelhece. Cadernos de Saúde Pública, São Paulo, v. 4, n. 4, p. 382-397, 1988.
WAGENAAR, D. B. et al. Late: life depression and mental health services in primary care. Journal of Psychiatric Neurology, v. 15, n. 3, p. 134-140, 2002.

WAITE, L. J.; GALLAGHER, M. The case for marriage: why married people are happier, healthier, and better off financially. Broadway, 272 f.; October 9, 2001.

WORDEN, J. W. Terapia do luto. 2. ed. Porto Alegre: Artes Médicas, 1998. 